\title{
Evaluation of the Color Durability of Acrylic Resin Veneer Materials after Immersion in Common Beverages at Different Time Intervals: A Spectrophotometric Study
}

\author{
Shivani Kohli ${ }^{1}$, Shekhar Bhatia ${ }^{2}$
}

Background: Proper function, esthetics, and cost are the prime factors to be considered while selecting bridge veneering materials. The purpose of the study is to evaluate color durability of acrylic veneer materials after immersion in common beverages at different time intervals.

Methods: Spectrophotometer was used for taking color measurements based on the transmission of light through the specimens made of the selected materials which were Tooth moulding powder (DPI) and Acrylux (Ruthinium). Thirty specimens of standardized dimensions were prepared from each material. The specimens were divided into three groups of 10 each. One group of each material was immersed in tea (TajMahal) and another group of each material in cola (Pepsi) as the staining solutions. The remaining group of 10 from each material served as control and was stored in distilled water. Color measurements were obtained pre-immersion, and after 1, 15, and 30 days of immersion.

Results: Tooth moulding powder displayed better color durability than Acrylux over the 1 month immersion period in both staining solutions. Tea resulted in more discoloration compared to cola (Pepsi).

Conclusion: The difference in the color durability of Acrylux and Tooth moulding powder may be attributed to the differences in the composition of tested resin veneering materials, i.e. their polar properties, which contribute to the absorption of staining solution, and the different brands and the strengths of the solutions.

(Biomed J 2015;38;244-249)

Key words: acrylic veneer, beverages, color difference, discoloration, time intervals

\begin{abstract}
At a Glance Commentary
Scientific background on the subject

Discoloration of resin veneering materials has always posed a perplexing problem to patients and clinicians when working in the esthetic zone. The habits of daily consumption of beverages like tea, coffee, and cola several times a day tend to stain and discolor resins. Both the concentration of the staining agent in beverages and the period of exposure may affect the pigmentation of resins. Minimal color change is an important factor that should be considered in the selection of veneering materials.
\end{abstract}

\section{What this study add to the field}

Numerous new-generation indirect resins are being used for complete contour restoration of teeth. Earlier indirect resin systems have been abortive in this application, due in part to color instability. Fixed prosthodontics materials must sustain long-term color stability in order to avoid replacement of restorations. Regardless of their chemical composition, dental resins tend to absorb liquids and change their color over time. Therefore, discoloration is one of the important variables that must be measured when choosing a material for long-lasting reconstructions. or the past 25 years, in the dental profession, synthetic
plastics have been thought of as the potential candi- date for the ideal restorative material. Many alterations in processing procedures and technical operations have been

From the ${ }^{1}$ Department of Prosthetic Dentistry and Crown and Bridge, MAHSA University, Kuala Lumpur, Malaysia; ${ }^{2}$ Department of Restorative Dentistry, School of Dentistry, International Medical University, Kuala Lumpur, Malaysia Received: Jun. 14, 2013; Accepted: Sep. 30, 2014

Correspondence to: Dr. Shivani Kohli, Department of Prosthetic Dentistry and Crown and Bridge, MAHSA University, Malaysia. 19A-4-4, Bangsar Permai, Jalan Tandok, Bangsar, Kuala Lumpur, Malaysia. Tel: 60-105472186; Fax: 60-320929945; E-mail: shivani@mahsa.edu.my

DOI: $10.4103 / 2319-4170.143519$ 
suggested and employed during this period. It is likely that a combination of factors and characteristic qualities of plastics contributes to the lack of complete success of plastics for the fixed type of restorations. The problem of color esthetics is essential in the fixed restoration than in the denture base of a removable appliance. ${ }^{[1]}$

Proper function, periodontal health, esthetics, and cost are the prime factors to be considered when selecting bridge veneering materials. Dental porcelain, acrylic and composite resins are the materials that are currently being used for veneering cast restorations.

Metal ceramic restorations have numerous undesirable characteristics: The opaque nature of the metal substructure does not simulate natural translucency; fabrication is time consuming and technically demanding, and the abrasiveness of porcelain is destructive when there are opposing natural dentition. ${ }^{[2]}$ The advantages of resin veneering materials include ease of fabrication, low cost, lack of wear to opposing dentition, and the ease of repair. ${ }^{[3]}$

Discoloration of resin-based veneer materials may be caused by various intrinsic and extrinsic factors. The intrinsic factors involve the discoloration of the resin material itself, such as the alteration of the resin matrix and of the interface of matrix and fillers. Chemical discoloration has been attributed to a change or oxidation of the amine accelerators, oxidation in the structure of the polymer matrix, and oxidation of unreacted pendant methacrylate groups. ${ }^{[4]}$

Extrinsic factors for discoloration include staining by adsorption and absorption of colorants as a result of contamination from exogenous sources. The staining of polymeric materials by colored solutions such as nicotine, coffee, tea, and other various beverages has been reported. The extent of discoloration in the oral cavity may be associated with dietary habits. ${ }^{[4]}$ Water accumulation and photooxidation has been reported to be responsible for internal color change. Water plays an important role in the chemical degradation process through oxidation, hydrolysis, and the subsequent change of the optical properties of the restorative materials. ${ }^{[5]}$

Several studies have been done on the color stability of resins used for provisional and fixed restoration, but very few focused on the acrylic resin veneering materials which are widely used. Therefore, in this study, we aimed to evaluate the effect of tea and cola on the color durability of materials used for bridge veneering.

\section{METHODS}

Two brands of acrylic resin used for veneering crown and bridge were selected for this study:

- Tooth moulding powder - Dental Product of India (DPI) of A shade

- Acrylux - Ruthinium of A1 shade (enamel).
Shades of the above-mentioned brands were selected to test color durability since the instrument (spectrophotometer) used for taking color measurements was based on transmission of light through the specimen.

Two staining solution used:
a. Tea (TajMahal)

b. Cola (Pepsi).

\section{Preparation of samples}

Thirty specimen disks of $15 \mathrm{~mm}$ diameter and $2 \mathrm{~mm}$ thickness were prepared from each material in the following way:

- A silicone mold of the specified dimensions was made to produce wax blocks. The wax blocks were invested in the denture processing flask to create mold space into which the resin was packed and processed in a water bath for $2 \mathrm{~h}$ at $70^{\circ} \mathrm{C}$, followed by post curing for $30 \mathrm{~min}$ at $100^{\circ} \mathrm{C}$.

- After deflasking, surface irregularities on the specimens and the excess material were trimmed off with an acrylic trimmer. All specimens were abraded on both sides with silicone carbide paper and finished.

- The specimens were then stored in distilled water at $37^{\circ} \mathrm{C} \pm 1^{\circ} \mathrm{C}$ for $24 \mathrm{~h}$ in the incubator. This rehydration process simulates the first day of service for restoration in the oral environment. It is known that the materials used in this study obtain most of their water during the first day of immersion.

- Ten randomly selected specimens from each material were immersed in each of the two staining solutions. The remaining 10 specimens from each material served as control and were stored in distilled water.

\section{Preparation of staining solutions}

- Cola (Pepsi) was used without any dilution.

- Tea solution was prepared by mixing $15 \mathrm{~g}$ of tea (TajMahal) in $500 \mathrm{ml}$ of boiling distilled water for 10 min.

\section{Method of staining}

- The test specimens were stored in the cola, tea solution, and distilled water, which were kept in the incubator for 1,15 , and 30 days. ${ }^{[6,7]}$

- Color measurements were made pre-immersion $\left(\mathrm{T}_{0}\right)$ and at 1 day $\left(\mathrm{T}_{1}\right), 15$ days $\left(\mathrm{T}_{2}\right)$, and 30 days $\left(\mathrm{T}_{3}\right)$.

- Before each measurement, the specimens were cleaned in distilled water for $5 \mathrm{~min}$ and dried with tissue paper.

\section{Color measurements}

The color and the color differences of each specimen were measured with a spectrophotometer (Minolta, CM-3301d). ${ }^{[8]}$ 
The testing apparatus had a measuring head aperture of $10 \mathrm{~mm}$ diameter. Measuring characteristics of the spectrophotometer were set to standard illuminant D6, which is intended to represent average daylight. The spectrophotometer was connected to a computer system. Before each measurement session, the spectrophotometer was calibrated according to the manufacturer's recommendations by using the supplied white calibration standard. The specimens were centered on the measuring head of the spectrophotometer. The color characteristics, tristimulus values $\mathrm{X}, \mathrm{Y}, \mathrm{Z}$, and $\mathrm{CIE}(\mathrm{Lab})$ of specimens of each brand of veneering materials, were evaluated.

The CIE Lab system is an approximately uniformed color space with coordinates for lightness, namely, white-black $\left(\mathrm{L}^{*}\right)$, redness-greenness $\left(\mathrm{a}^{*}\right)$, and yellowness-blueness $\left(b^{*}\right)$. This system makes it possible to evaluate the amount of perceptible color change in each sample. L, a, and $b$ values of each specimen before immersion $\left(\mathrm{T}_{0}\right)$ and after immersion at each specified time interval $\left(\mathrm{T}_{1}, \mathrm{~T}_{2}, \mathrm{~T}_{3}\right)$ were measured by placing each specimen on the measuring head while it is covered with the black cover.

The mean values of $\Delta \mathrm{L}^{*}, \Delta \mathrm{a}^{*}$, and $\Delta \mathrm{b}^{*}$ after measurements were automatically calculated by the spectrophotometer and recorded. ${ }^{[4]}$ Color difference $\left(\Delta \mathrm{E}^{*}\right)$ was calculated from the mean $\Delta \mathrm{L}^{*}, \Delta \mathrm{a}^{*}$, and $\Delta \mathrm{b}^{*}$ values for each specimen with the formula:

$$
\Delta \mathrm{E}^{*}=\sqrt{ }\left(\Delta \mathrm{L} *^{2}+\Delta \mathrm{a} *^{2}+\Delta \mathrm{b}^{*^{2}}\right)
$$

All the readings were recorded and used for the statistical analysis.

\section{Statistical analysis}

1. One-way analysis of variance

2. Unpaired $t$-test

Mean $\Delta \mathrm{E}$ values and standard deviations are compared using a one-way analysis of variance (ANOVA) to determine the effect of different beverages at different time intervals on the color of the specimen groups ${ }^{[4]}$ ANOVA revealed interactions between time and material; a least-squared mean test was used to determine significant differences $(p \leq 0.05)$ among the materials. Individual coordinate differences were analyzed in the same manner.

\section{RESULTS}

All the specimens were checked for their color differences $(\Delta \mathrm{E})$ using a spectrophotometer and the readings were recorded [Tables 1-5].

Tea and cola caused considerable discoloration to the acrylic resin veneering materials. Tea solution caused more discoloration compared to cola. The maximum color difference $(\Delta \mathrm{E})$ was noted for Acrylux in tea solution (highly significant). The $x$-axis shows Acrylux and Tooth moulding

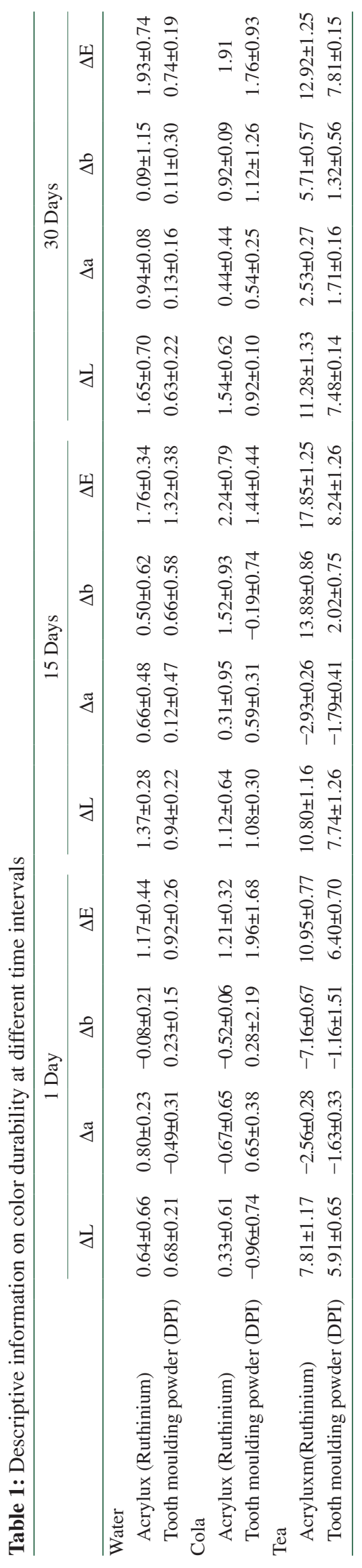


Table 2: Descriptive statistics on overall color durability in different beverages

\begin{tabular}{llccc}
\hline Beverages & Materials & $\Delta \mathrm{E} 1$ day & $\Delta \mathrm{E} 15$ days & $\Delta \mathrm{E} 30$ days \\
\hline Water & Acrylux (Ruthinium) & $1.17 \pm 0.44$ & $1.76 \pm 0.34$ & $1.93 \pm 0.74$ \\
& Tooth moulding & $0.92 \pm 0.26$ & $1.32 \pm 0.38$ & $0.74 \pm 0.19$ \\
& powder (DPI) & & & \\
Cola & Acrylux (Ruthinium) & $1.21 \pm 0.32$ & $2.24 \pm 0.79$ & $1.91 \pm 0.54$ \\
& Tooth moulding & $1.96 \pm 1.68$ & $1.44 \pm 0.44$ & $1.76 \pm 0.93$ \\
& powder (DPI) & & & \\
Tea & Acrylux (Ruthinium) & $10.95 \pm 0.77$ & $17.85 \pm 1.25$ & $12.92 \pm 1.25$ \\
& Tooth moulding & $6.40 \pm 0.70$ & $8.24 \pm 1.26$ & $7.81 \pm 0.15$ \\
& powder (DPI) & & & \\
\hline
\end{tabular}

Table 3: Acrylux (Ruthinium) vs. Tooth moulding powder (DPI)

\begin{tabular}{|c|c|c|c|c|c|}
\hline & \multirow[t]{2}{*}{$\begin{array}{c}\text { Acrylux } \\
\text { (Ruthinium) }\end{array}$} & \multirow{2}{*}{$\begin{array}{l}\text { Tooth } \\
\text { moulding } \\
\text { powder } \\
(\mathrm{DPI})\end{array}$} & \multirow[t]{2}{*}{$\begin{array}{c}\text { Mean } \\
\text { difference }\end{array}$} & \multicolumn{2}{|c|}{$\begin{array}{c}\text { Acrylux (Ruthinium) } \\
\text { vs. Tooth moulding } \\
\text { powder (DPI) }\end{array}$} \\
\hline & & & & $t$-value* & $p$ \\
\hline \multicolumn{6}{|l|}{ Water } \\
\hline$\Delta \Delta \mathrm{E} 1$ day & $1.71 \pm 0.44$ & $0.92 \pm 0.26$ & 0.25 & 1.55 & $0.14, \mathrm{NS}$ \\
\hline$\Delta \mathrm{E} 15$ days & $1.76 \pm 0.34$ & $1.32 \pm 0.38$ & 0.44 & 2.71 & $<0.05, \mathrm{~S}$ \\
\hline$\Delta$ E 30 days & $1.93 \pm 0.74$ & $0.74 \pm 0.19$ & 1.19 & 6.05 & $<0.01, \mathrm{~S}$ \\
\hline \multicolumn{6}{|l|}{ ANOVA $^{* *}$} \\
\hline$F$ & $>0.30$ & 10.64 & - & - & - \\
\hline$p$ & $<0.01, \mathrm{~S}$ & $<0.01, \mathrm{~S}$ & & & \\
\hline \multicolumn{6}{|l|}{ Cola } \\
\hline$\Delta \mathrm{E} 1$ day & $1.21 \pm 0.32$ & $1.96 \pm 1.68$ & 0.75 & 1.38 & $0.20, \mathrm{NS}$ \\
\hline$\Delta \mathrm{E} 15$ days & $2.24 \pm 0.79$ & $1.44 \pm 0.44$ & 0.80 & 2.86 & $<0.05, \mathrm{~S}$ \\
\hline$\Delta \mathrm{E} 30$ days & $1.91 \pm 0.54$ & $1.76 \pm 0.93$ & 0.15 & 0.46 & $0.66, \mathrm{NS}$ \\
\hline \multicolumn{6}{|l|}{ ANOVA } \\
\hline$F$ & 8.03 & 0.67 & - & - & - \\
\hline$p$ & $<0.01, \mathrm{~S}$ & $0.52, \mathrm{NS}$ & & & \\
\hline \multicolumn{6}{|l|}{ Tea } \\
\hline$\Delta \mathrm{E} 1$ day & $10.95 \pm 0.77$ & $6.40 \pm 0.70$ & 4.55 & 13.85 & $<0.01, \mathrm{~S}$ \\
\hline$\Delta \mathrm{E} 15$ days & $17.85 \pm 1.25$ & $8.24 \pm 1.26$ & 9.61 & 17.13 & $<0.01, \mathrm{~S}$ \\
\hline$\Delta \mathrm{E} 30$ days & $12.92 \pm 1.25$ & $7.81 \pm 0.15$ & 5.11 & 12.86 & $<0.01, \mathrm{~S}$ \\
\hline \multicolumn{6}{|c|}{ ANOVA } \\
\hline$F$ & 103.4 & 13.16 & - & - & - \\
\hline$p$ & $<0.01, \mathrm{~S}$ & $<0.01, \mathrm{~S}$ & & & \\
\hline
\end{tabular}

${ }^{*}$ Unpaired $t$-test, ${ }^{* *}$ One-way ANOVA, Abbreviations: S: Significant; NS: Not significant; Analysis of variance; HS: Highly significant; S: Significant

powder immersion in different staining solutions at varying time intervals and the $y$-axis shows the mean $\Delta \mathrm{E}$ in Figure 1. Tooth moulding powder (DPI) demonstrated better color durabilty than Acrylux (Ruthinium) over the 1 month immersion period in both staining solutions.

\section{DISCUSSION}

Crown and bridge plastics have been typically formulated from methyl methacrylate or triethylene glycol dimethacrylate and poly (methyl methacrylate) polymer ${ }^{[9]}$ In vitro tests offer

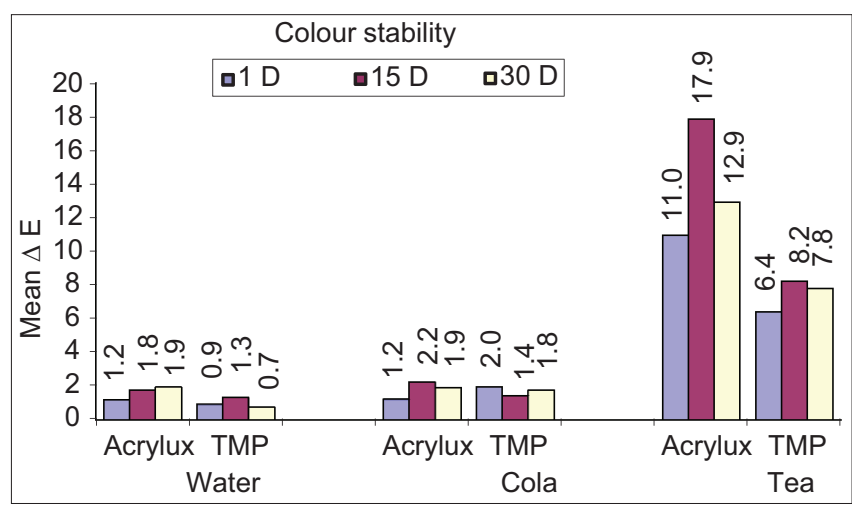

Figure 1: Comparison of color durability of resin veneering materials in different beverages at different time intervals.

an opportunity to observe the behavior of resin after artificial aging and staining with different pigments. This observation is difficult or even impossible in clinical conditions. ${ }^{[10]}$

In assessing chromatic differences, two color systems are commonly used: Munsell color system and Standard Commission International de L'Eclairage (CIE Lab). In the present study, CIE Lab color system was used to evaluate color stability because this color system can translate spectrophotometer data to a uniformed color space. The color space $\mathrm{L}^{*}$ (lightness), $\mathrm{a}^{*}$ (red-green), and $\mathrm{b}^{*}$ (yellow-blue) are the chromatic coordinates which indicate color direction. ${ }^{[11]}$

Most materials used for restorations are subjected to sorption, a process of absorption and adsorption of liquid dependent upon environmental conditions. Actual color changes occur due to the chemical reactions of the materials themselves. Technique variables that result in porosity or a surface quality conducive to the accumulation of debris may lead to significant discoloration. ${ }^{[6]}$

Fluid pigments from food, beverages, drugs, and nicotine are deposited in the interprismatic space of the conservative and prosthetic restorations, especially on acrylic resins which are more porous than resin composite and reinforced resins. The combination of the dietary chromogens present mainly in tea and coffee can cause surface precipitation reaction without the formation of metal sulfides. Both the concentration of the staining agent and the period of exposure may affect the degree of pigmentation of an acrylic resin. The role of finishing and polishing is crucial in reducing pigmentation. ${ }^{[12]}$

Staining of resins is also dependent on the contact angle and water sorption. Most hydrophobic resins show the highest contact angle and lowest water sorption due to the absence of hydroxyl group in their composition, whereas hydrophilic resins show the lowest contact angle and highest water sorption due to the presence of hydroxyl group..$^{[13]}$

If the material is to be used as esthetic veneering resin for casting, it should be restricted to non-occlusal load areas to prevent permanent deformation, fracture, or early loss of 
Table 4: Color durability of resin veneering materials in different beverages

\begin{tabular}{|c|c|c|c|c|c|c|}
\hline & \multicolumn{3}{|c|}{ Acrylux (Ruthinium) } & \multicolumn{3}{|c|}{ Tooth moulding powder (DPI) } \\
\hline & $\Delta \mathrm{E} 1$ day & $\Delta \mathrm{E} 15$ days & $\Delta \mathrm{E} 30$ days & $\Delta \mathrm{E} 1$ day & $\Delta \mathrm{E} 15$ days & $\Delta \mathrm{E} 30$ days \\
\hline Water & $1.17 \pm 0.44$ & $1.76 \pm 0.34$ & $1.93 \pm 0.60$ & $0.92 \pm 0.26$ & $1.32 \pm 0.38$ & $0.74 \pm 0.19$ \\
\hline Cola & $1.21 \pm 0.32$ & $2.24 \pm 0.79$ & $1.91 \pm 0.54$ & $1.96 \pm 1.68$ & $1.44 \pm 0.44$ & $1.76 \pm 0.93$ \\
\hline Tea & $10.95 \pm 0.77$ & $17.85 \pm 1.25$ & $12.92 \pm 1.25$ & $6.40 \pm 0.70$ & $17.85 \pm 1.25$ & $7.81 \pm 0.15$ \\
\hline \multicolumn{7}{|c|}{ ANOVA } \\
\hline$F$ & 1074.4 & 1093.0 & 547.7 & 75.3 & 247.2 & 474.6 \\
\hline$p$ & $<0.001, \mathrm{HS}$ & $<0.001$, HS & $<0.001, \mathrm{HS}$ & $<0.001$, HS & $<0.001, \mathrm{HS}$ & $<0.001$, HS \\
\hline
\end{tabular}

Abbreviations: HS: Highly significant; ANOVA: Analysis of variance

Tables 5: Comparison of color durability between different beverages

\begin{tabular}{|c|c|c|c|c|c|c|}
\hline & \multicolumn{3}{|c|}{ Acrylux (Ruthinium) } & \multicolumn{3}{|c|}{ Tooth moulding powder (DPI) } \\
\hline & $\Delta \mathrm{E} 1$ day & $\Delta \mathrm{E} 15$ days & $\Delta \mathrm{E} 30$ days & $\Delta \mathrm{E} 1$ day & $\Delta \mathrm{E} 15$ days & $\Delta \mathrm{E} 30$ days \\
\hline \multicolumn{7}{|c|}{ Difference between groups ( $p$ values) } \\
\hline Water-cola & $0.98, \mathrm{NS}$ & $0.94, \mathrm{NS}$ & $0.99, \mathrm{NS}$ & $0.09, \mathrm{NS}$ & $0.94, \mathrm{NS}$ & $<0.01, \mathrm{~S}$ \\
\hline Water-tea & $<0.001$, HS & $<0.001, \mathrm{HS}$ & $<0.001$, HS & $<0.001$, HS & $<0.001$, HS & $<0.001, \mathrm{HS}$ \\
\hline Cola-tea & $<0.001, \mathrm{HS}$ & $<0.001$, HS & $<0.001$, HS & $<0.001$, HS & $<0.001$, HS & $<0.001, \mathrm{HS}$ \\
\hline
\end{tabular}

Abbreviations: S: Significant; NS: Not significant; HS: Highly significant

the material from accelerated wear. The high thermal expansion observed with such materials may lead to an uptake of oral fluid at the veneer substrate interface leading to early discoloration of the veneer. Thermal cycling may also jeopardize the bonding of the veneering to the casting substrate. ${ }^{[3]}$

In dentistry, a discoloration that is more than perceptible $\left(\Delta \mathrm{E}_{\mathrm{ab}}^{*}>1.0\right)$ is acceptable up to the value $\Delta \mathrm{E}_{\mathrm{ab}}^{*}=3.3$, which is considered to be the upper limit of acceptability in subjective visual evaluations. Discoloration above this level is generally considered unacceptable. ${ }^{[4]}$

The soluble components of tea with blue absorption appeared as yellow as it is the complementary color to blue. The different reverse-phase liquid chromatographic retention times for these components of tea revealed that the yellow colorants have different polarities. The materials with high value for water sorption showed relatively high discoloration values in all staining solutions. Therefore, the discoloration of materials by tea is mainly due to surface adsorption of the colorants. ${ }^{[4]}$

Malvin et al. conducted a study to evaluate the color stability of restorative materials when exposed to cola beverages. Seventy-two hours of cola exposure resulted in significant color change, including gray level and chromaticity, both as a function of materials and their shades.

This present study is in agreement with the reports given by Koumjian et al, ${ }^{[14]}$ Yannisakis, ${ }^{[7]}$ and Robert Scottie et al. $^{[12]}$

The present study revealed the effect of tea and cola on color durabilty of two brands of acrylic resin veneering materials. The standard deviation observed in the results compared with that of experimental error was attributed to the composition of the material and the immersion procedure (time and staining solutions).
No significant color differences caused by staining solutions were observed after day 1 of immersion $(p>0.05)$.

After 15 days of immersion, both the resins demonstrated unacceptable color changes, with tea demonstrating more discoloration which was highly significant $(p<0.01)$. Changes observed in cola were minimal $(p>0.05)$.

At the $30^{\text {th }}$ day, there was significant increase in the absorbance value (color change) for both the tested materials in the tea solution. This conforms with the findings of previous reports by Ruyter ${ }^{[4]}$ and Crispin and Caputo ${ }^{[6]}$ Cola produced significant color change in Acrylux but very little change in Tooth moulding powder.

The difference in the color durabity of Acrylux (Ruthinium) and Tooth moulding powder (DPI) may be attributed to the differences in the following:

- Composition of the tested resin veneering materials, i.e, Acrylux has poly (methyl methacrylate) with a high molecular weight compared to Tooth moulding powder

- Polar properties and degree of polymerization of the tested resin veneering materials, which contribute to absorption of the staining solution ${ }^{[4]}$

- Brands and strength of staining solutions. ${ }^{[7]}$

In the present study, tea solution was prepared by mixing tea leaves directly with water as is done in most Indian households. So, the surface area of tea leaves in contact with water is more in the present study which could have led to preparation of stronger tea solution that caused more staining of the acrylic resins. ${ }^{[7]}$

Most soft drinks are acidic in nature and exposure to these drinks may result in erosion. The type of acid, total 
acid level, and calcium chelating properties may play an important role. This dissolution of restorative material is also influenced by $\mathrm{pH}$. Intraorally, it is very difficult to calculate the specific period during which the restorative material in the human mouth is exposed to these acidic beverages. The total exposure time would depend on the actual amount of beverage consumed, the frequency of consumption (i.e, if small sips are taken at frequent intervals or the entire can/bottle is consumed quickly), the mode of ingestion (i.e, straw, which reduces the exposure as a result), and so forth. $^{[15]}$

The long-term immersion (30 days) represents the cumulative effect of repeated short immersions of prosthesis during prolonged service. ${ }^{[7]}$ The duration (1 month) for which the study was carried out would probably correspond to 4 years of clinical use. However, this does not include the other kinds of stresses, i.e. exposure to occlusal forces, tooth brush abrasion, food colorants, and light under wet conditions.

The present study is an in vitro test which is accelerated as compared to clinical conditions. The results show significant color change in acrylic resin within few days of immersion in tea. Also, 15-30 days of immersion in cola would be approximately equal to 10 months of clinical exposure to tea and approximately 2 years of exposure to cola. Time was found to be a critical factor for color durabilty of acrylic resin veneering materials. Unpaired $t$-test showed that as immersion time increased, the color changes became more intensive.

Combinations of staining solution, immersion time, and absence of sufficient cleaning or brushing of the specimen during the study were significant factors affecting susceptibility to staining of the materials. However, actual staining in the oral cavity very likely requires longer period of time due to various reasons such as the intermittent nature of stain exposure, the dilution of staining media by saliva and other fluids, and the polishing of prosthesis by tooth brushing. ${ }^{[4,7,16]}$

\section{REFERENCES}

1. Peyton FA, Craig RG. Current evaluation of plastic in crown and bridge prosthesis. J Prosthet Dent 1963;13:743-53.

2. Douglas RD. Color stability of new generation indirect resins for prosthodontic application. J Prosthet Dent 2000;83:166-70.

3. Greener E, Duke S. Physical properties of 2 new crown and bridge veneering resins. J Oral Rehabil 1989;16:203-9.

4. Um CM, Ruyter IE. Staining of resin-based veneering materials with coffee and tea. Quintessence Int 1991;22:377-86.

5. Sham AS, Chu FC, Chai J, Chow TW. Color stability of provisional prosthodontic materials. J Prosthet Dent 2004;91:447-52.

6. Crispin BJ, Caputo AA. Color stability of temporary restorative materials. J Prosthet Dent 1979;42:27-33.

7. Yannikakis SA, Zissis AJ, Polyzois GL, Caroni C. Color stability of provisional resin restorative materials. J Prosthet Dent 1998;80:533-9.

8. Guler AU, Yilmaz F, Kulunk T, Guler E, Kurt S. Effect of different drinks on stainability of resin composite provisional restorative materials. J Prosthet Dent 2005;94:118-24.

9. Powers JM., Fan PL. Color stability and aging of plastic veneering materials. J Dent Res 1981;60:1692-6.

10. Jurgen S, Engel E. Invivo color stability of resin veneered telescopic dentures. J Prosthet Dent 1997;77:486-91.

11. Anusavice KJ, Phillip's. Science of dental materials. $11^{\text {th }}$ ed. Philadelphia: W.B. Saunders; 2003. p. 46-52.

12. Scotti R, Mascellani SC, Forniti F. The in vitro color stability of acrylic resins for provisional restorations. Int J Prosthodont 1997; 10:164-8.

13. Satau N, Khan AM, Matsumae I, Satou J, Shintani H. In vitro color change of composite based resins. J Dent Mater 1989;5:384-7.

14. Koumjian JH, Firtell DN, Nimmo A. Color stability of provisional materials in vivo. J Prosthet Dent 1991;65:740-2.

15. Jain P, Nihill P, Sobkowski J, Agustin MZ. Commercial soft drinks: $\mathrm{pH}$ and in vitro dissolution of enamel. Gen Dent 2007;55:150-4.

16. Mohan M, Shey Z, Vaidyanathan J, Vaidyanathan TK, Munisamy S, Janal M. Color changes of restorative materials exposed invitro to cola beverages. Pediatr Dent 2008;30:309-16. 